
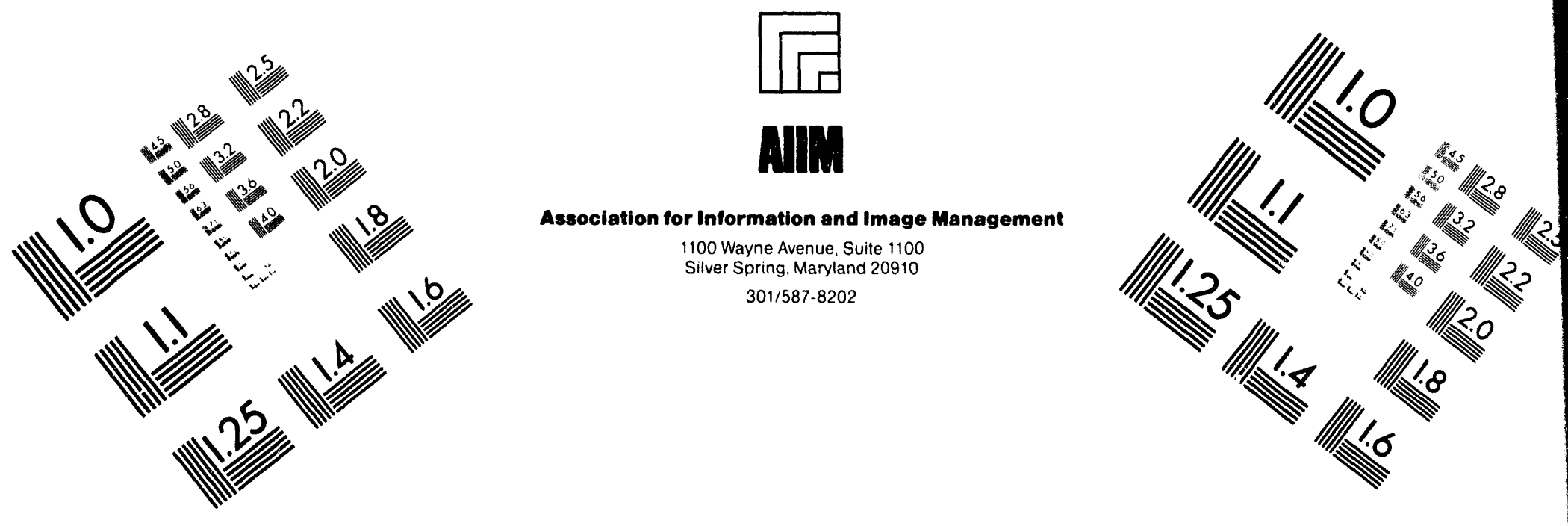

\title{
Centimeter
}

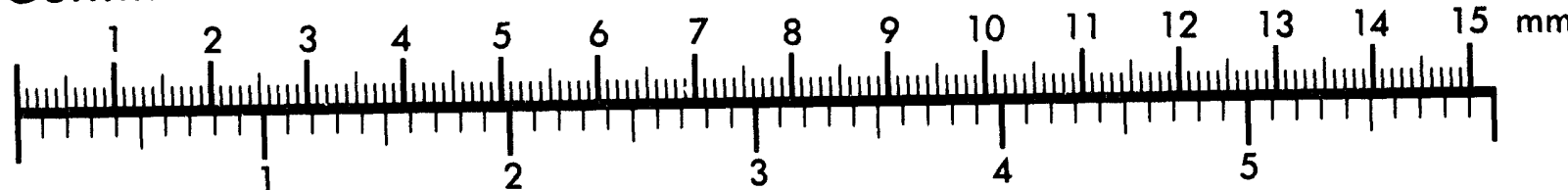

Inches
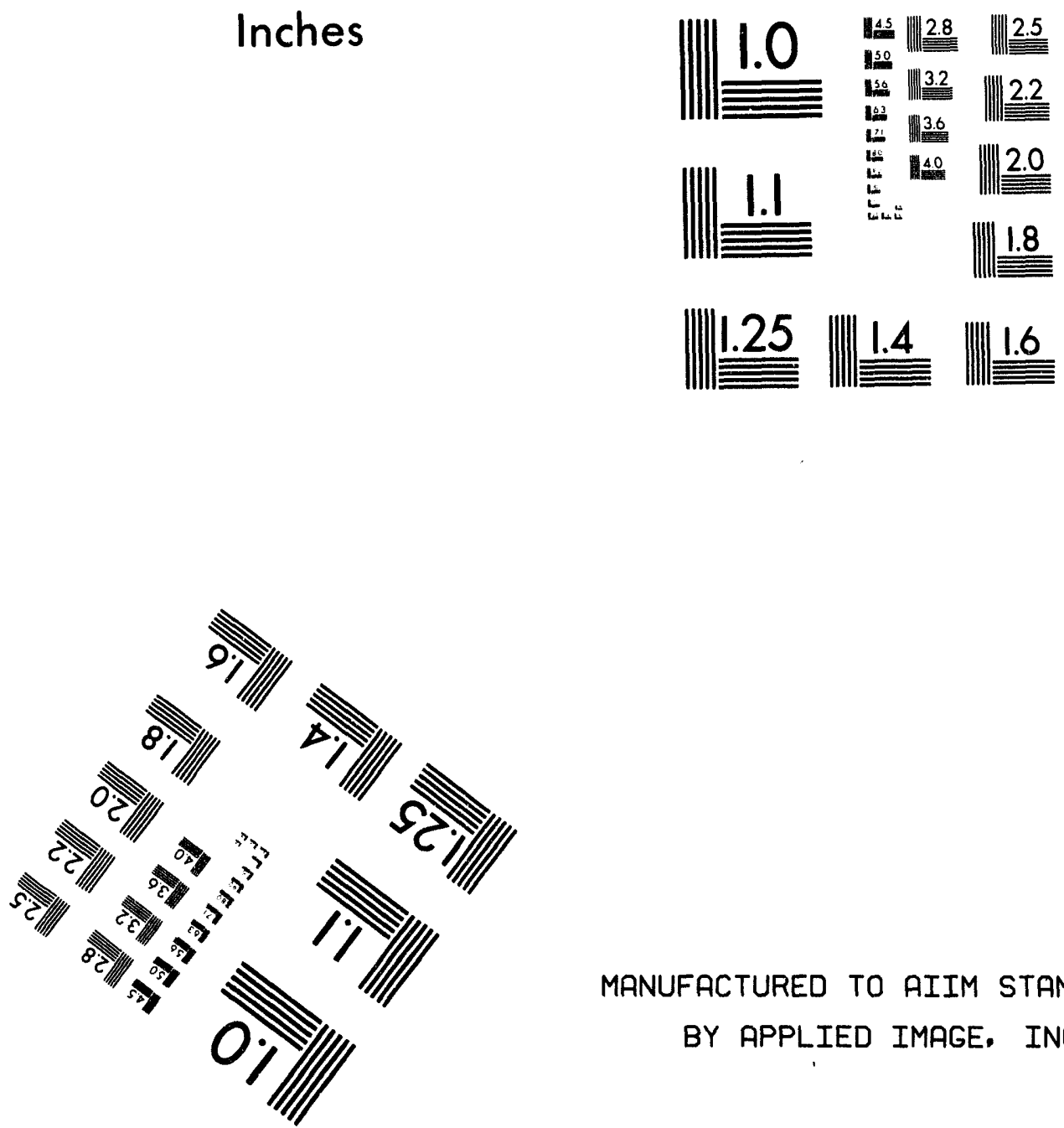

MANUFACTURED TO AIIM STANDARDS

BY APPLIED IMAGE, INC.

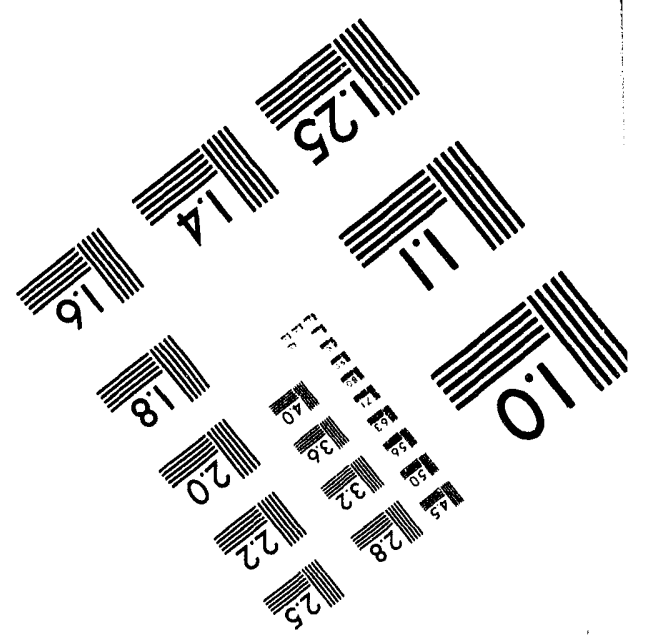



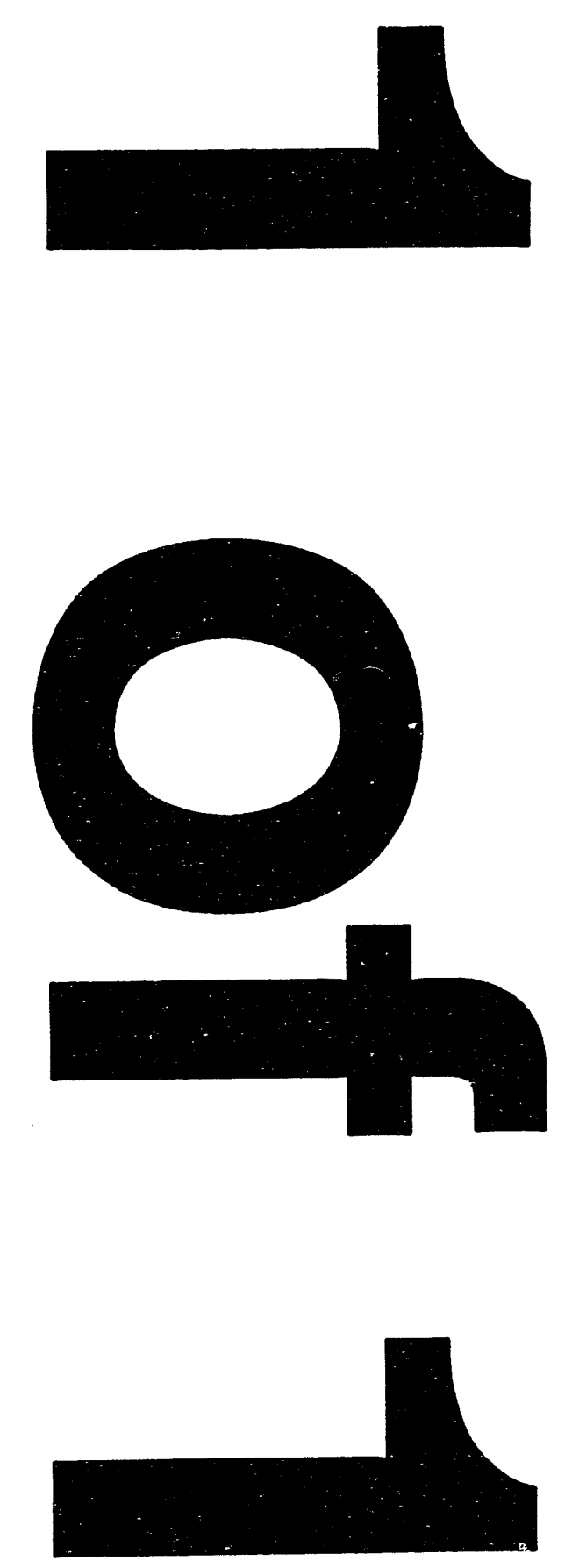


\section{SLOW BEAM RASTER SYSTEM AT CEBAF*}

C. Yan, J. Beaufait, R. Carlini, C. Cuevas, W. Vulcan, R. Wines CEBAF, 12000 Jefferson Avenue, Newport News, VA 23606, U.S.A.

July 7,1994

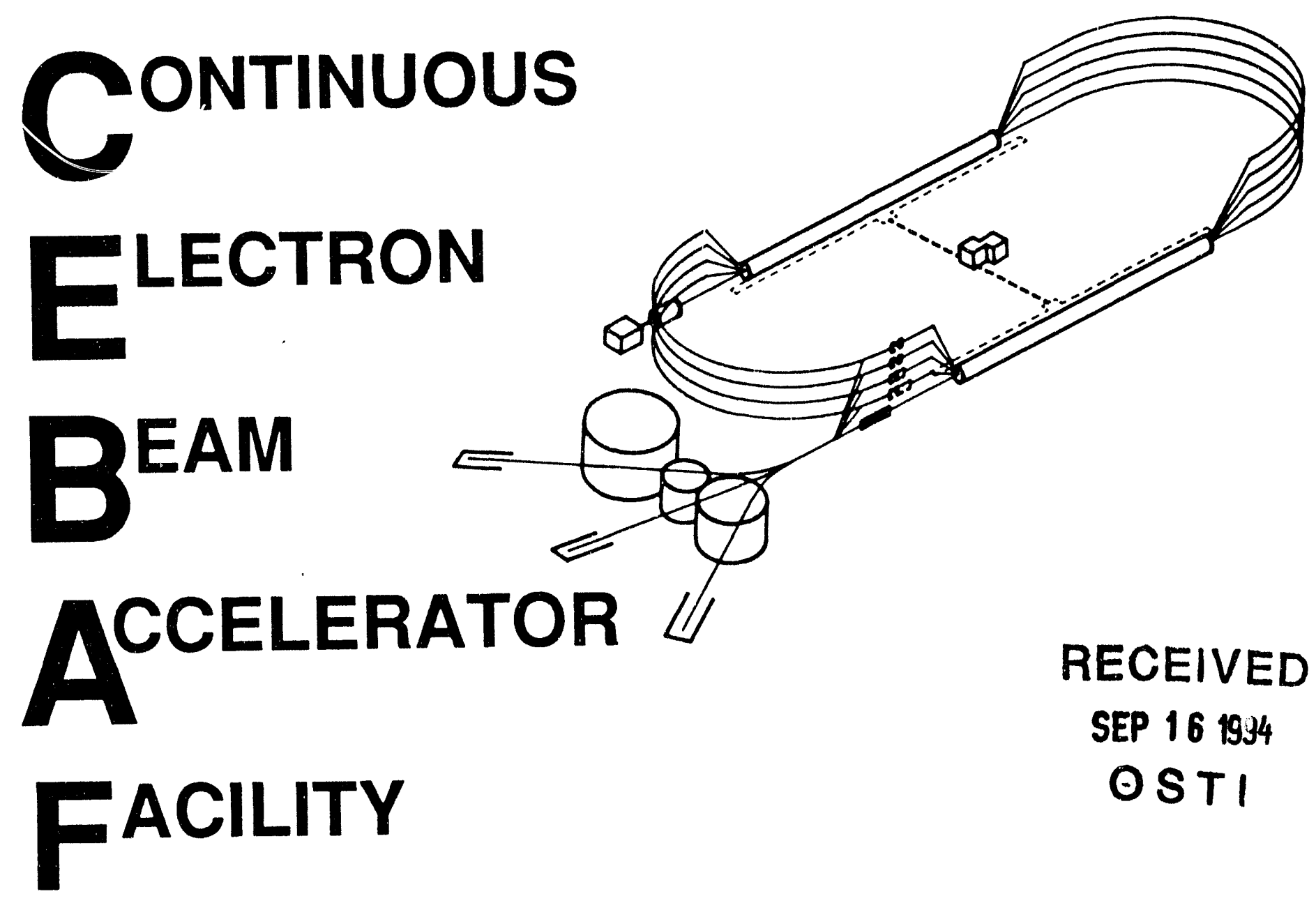

SURA Southeastern Universities Research Association

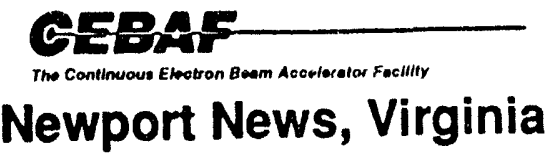
W 45 
Copies available from:

\author{
Library \\ CEBAF \\ 12000 Jefferson Avenue \\ Newport News \\ Virginia 23606
}

The Southeastern Universities Research Association (SURA) operates the Continuous Electron Beam Accelerator Facility for the United States Department of Energy under contract DE-AC05-84ER40150.

DISCLAIMER

This report was prepared as an account of work sponsored by the United States government. Neither the United States nor the United States Department of Energy, nor any of their employees, makes any warranty, express or implied, or assumes any legal liability or responsibility for the accuracy, completeness, or usefulness of any information, apparatus, product, or process disclosed, or represents that its use would not infringe privately owned rights. Reference herein to any specific commercial product, process, or service by trade name, mark, manufacturer, or otherwise, does not necessarily constitute or imply its endorsement, recommendation, or favoring by the United States government or any agency thereof. The views and opinions of authors expressed herein do not necessarily state or reflect those of the United States government or any agency thereof. 


\title{
Slow Beam Raster System at CEBAF *
}

\author{
C. Yan, J. Beaufait, R. Carlini, C. Cuevas, W. Vulcan, R. Wines \\ CEBAF, 12000 Jefferson Avenue, Newport News, VA 23606, U.S.A.
}

\section{Abstract}

A bedstead air-core raster magnet is being installed now, it will be used at CEBAF to scan the beam on the Hall $\mathrm{C}$ polarized target and the beam dump with fixed frequency 60

. $\mathrm{Hz}$ in horizontal, $103.4 \mathrm{~Hz}$ in vertical. The $\mathrm{x}$ and $\mathrm{y}$ raster magnets are driven by Variac transformer and SUMITOMO inverter respectively. Both of them provide an approximately sine current waveform with peak current 20 $\mathrm{A}$, corresponding to a maximum deflection angle $1 \mathrm{mr}$.

\section{INTRODUCTION}

The maximum beam power carried by $200 \mu \mathrm{A} 4 \mathrm{GeV} \mathrm{CE}$ BAF beam will be $800 \mathrm{~kW}$. The beam interaction with different materials was discussed in previous paper [1]. For an instantaneous spot size of $100 \mu \mathrm{m}$, the critical time constant for drilling a hole into the window by CEBAF 200 $\mu \mathrm{A}$ electron beam is about $100 \mu \mathrm{s}$. Also, any metal window material loses its strength after an energy deposition of $10^{18} \mathrm{ergs} / \mathrm{gram}$ by the beam. Therefore, the beam rastering speed and pattern have to be selected carefully to avoid long dwell times. Tentatively, an average beam spot size of $4 \times 4 \mathrm{~cm}^{2}$ at beam dump was adopted.

The Hall $\mathrm{C}$ polarized target will have a useful width and height of $2.5 \mathrm{~cm}$. To make full use of it, the rastering of the beam on the target should cover at least $2.5 \times 2.5 \mathrm{~cm}^{2}$. Both of beam dump and polarized target require raster magnet having a maximum angular deflection $1 \mathrm{mr}$ for 6 $\mathrm{GeV}$ electron beam. Table 1.' gives rastering parameters required by different target materials.

\section{RASTER MAGNET DESIGN BY TOSCA}

- Bedstead air core coils are selected as the raster magnets. The bedstead is made up of eight straight sections and eight 90 degree arcs. The cross section is rectangular, defined by its width in local $x$ direction and thickness in local y direction. The TOSCA design specifications of slow raster coils are listed in Table 2.

The geometry of slow raster magnet is shown in Figure 1. The bedstead shape of the raster coil will generate larger uniform field region than flat coil, and keep the high order field components, mainly the sextupole component, as small as possible. The coil with constant perimeter ends

\footnotetext{
"This work was supported by the U.S. Department of Energy, under contract No. DE-AC05-84ER40150
}

Table 1: Parameters of slow raster magnet

\begin{tabular}{|l|c|c|}
\hline $\begin{array}{l}\text { Destination } \\
\text { of rastering }\end{array}$ & $\begin{array}{c}\text { Polarized } \\
\text { Target }\end{array}$ & $\begin{array}{c}\text { Beam Dump } \\
\text { materials }\end{array}$ \\
\hline Position $(\mathrm{m})$ & 142.59 & 200.65 \\
Beam Current $(\mu \mathrm{A})$ & 0.1 & 200 \\
Rastering Area $(\mathrm{cm} 2)$ & $2.5 \times 2.5$ & $4.0 \times 4.0$ \\
Rastering Frequen $\mathrm{v}(\mathrm{Hz})$ & $60 / 103.4$ & $60 / 103.4$ \\
\hline
\end{tabular}

Table 2: Specification of SR magnet

\begin{tabular}{|l|c|}
\hline Design Parameter & Slow Raster \\
\hline Central field (Gauss) & 438.8 \\
Bending angle at 6 GeV & $0.84 \mathrm{mr}$ \\
J Bdl (kG cm) & 16.8 \\
Field uniformity & $10^{-2}$ \\
Effective length (cm) & 38.34 \\
Physical dimension $(\mathrm{cm})$ & 48 \\
Inner radius $(\mathrm{cm})$ & 1.905 \\
Number of turns & 200 \\
Ampere-turns $(\mathrm{A}-\mathrm{T})$ & 4000 \\
Current density $\left(\mathrm{A} / \mathrm{cm}^{2}\right)$ & 148 \\
Stored energy (Joules) & 6.944 \\
Inductance $(\mathrm{H})$ & $34.7 \times 10^{-3}$ \\
DC resistance $(\Omega)$ & 0.916 \\
RMS power $(\mathrm{kW})$ & 2.18 \\
Type of conductors & Awg $6 \mathrm{square}$ \\
Rastering frequency $(\mathrm{Hz})$ & $60 / 103.4$ \\
\hline
\end{tabular}




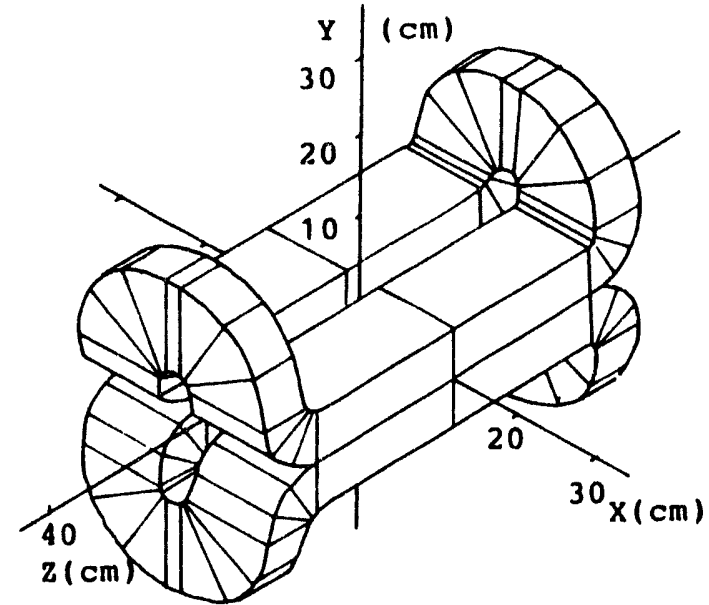

Figure 1: TOSCA layout of the slow raster raster magnet (SR).

has higher efficiency than bedstead coil, but it doesn't fit beam pipe geometry.

The bedstead air-core coils are manufactured by Applied Magnetic Products. The first slow raster magnet is shown in Figure 2.

\section{DRIVERS FOR SLOW RASTER MAGNETS}

The frequency ratio between horizontal and the vertical rastering is selected in such a way that a fast rolling pattern is generated, therefore, the density distribution over entire scanning area becomes uniform just after few cycles, it is much faster than TV scan pattern. The rastering pattern is illustrated in Figure 3.

Triangle wavefor $\omega_{*}$ is originally preferable to drive the raster coil because there is no slow down area near each turning point. In fact, it is difficult to design a triangle current driver with $\pm 20 \mathrm{~A}$ capability because of the large inductance of the coils. A Volt-Pac variable transformer (9T92A77) is used as $60 \mathrm{~Hz}, 20 \mathrm{~A}$ current driver. Current waveform is obtained from LEM LA 55-P current sensor, which is a current transducer for the electronic measurement of currents (DC, AC and pulsed) with galvanic isolation between the primary (measured) and the analog output (control) signal. Its measuring range covers 0 to $\pm 70 \mathrm{~A}$ with turns reduction ratio $1: 1000$. The linearity is better than $0.15 \%$, response time is better than 500 ns. The di/dt accurately followed is better than $200 \mathrm{~A} / \mu \mathrm{s}$, and its bandwidth is from 0 to $200 \mathrm{kHz}(-1 \mathrm{~dB})$.

A pulse-width modulation (PWM) power amplifier (SUMITOMO AF504-011) is used to drive horizontal raster magnet at $103.4 \mathrm{~Hz}$. The superiority of pulsewidth modulation (PWM) power amplifier to linear amplifier technology is particularly striking when the need is to drive $\mathrm{AC}$ magnetic coils with high inductance and low

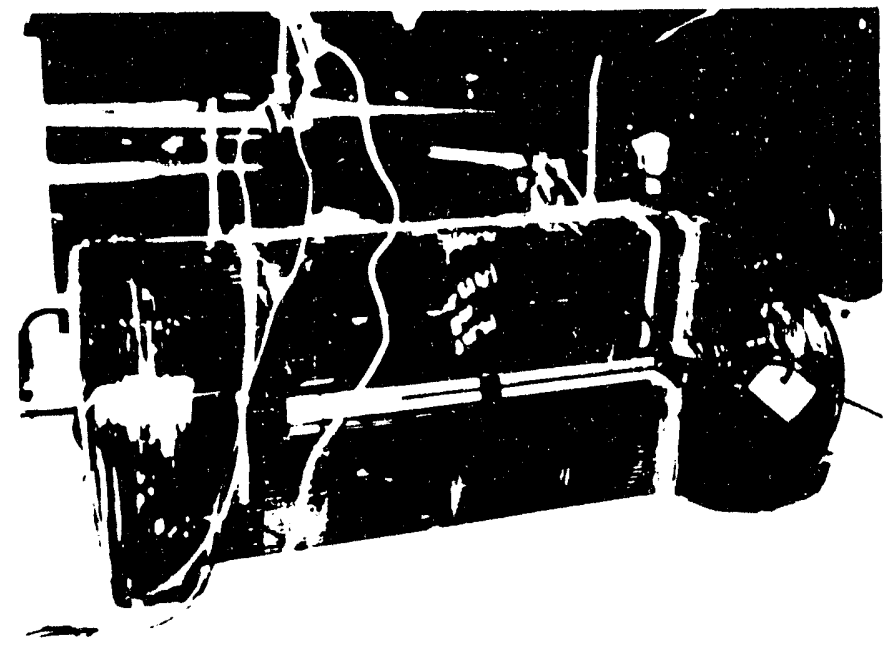

Figure 2: Slow raster magnet with current transducer and Hall probe mapping device

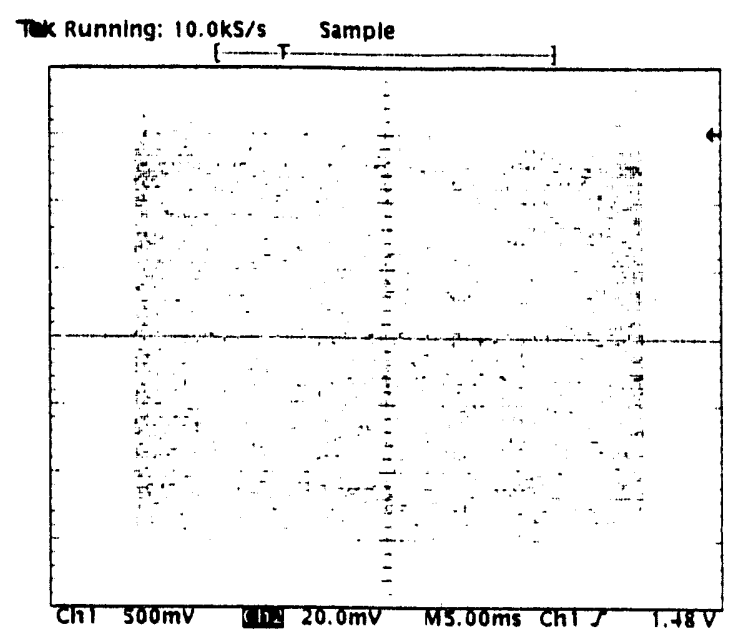

Figure 3: Rastering pattern of slow raster system 


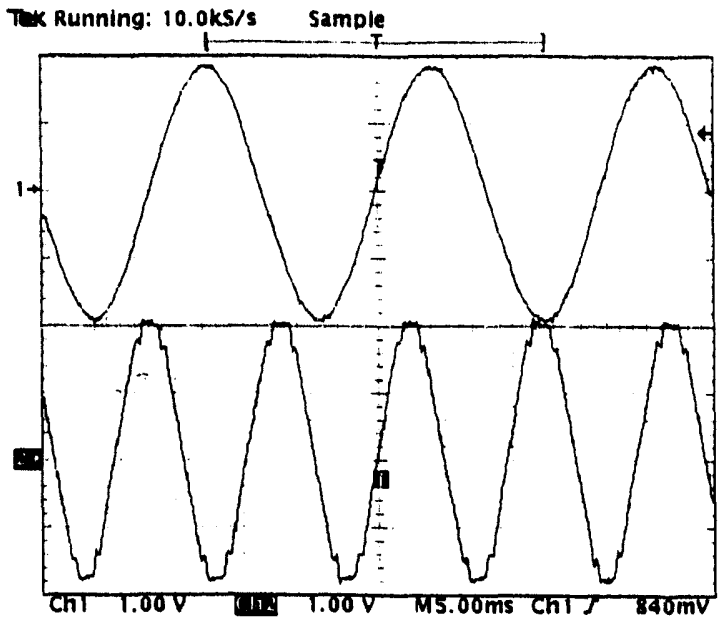

Figure 4: $60 \mathrm{~Hz}$ and $103.4 \mathrm{~Hz}$ current waveforms from LEM sensors

ohmic resistance, which is just the case of slow raster magnets. The current waveforms from LEM sensor are shown in Figure 4. At $103.4 \mathrm{~Hz}$ the output sine waveform is encompassed by stair shape wave modulated by a $3.7 \mathrm{KHz}$ chop frequency. At each step there is a $270 \mu$ s plateau between two spikes and the length of flat top is $1.34 \mathrm{~ms}$. This is the major drawback of PWM power driver. As the result of such highly distorted current waveform there is a density enhancement alone the horizontal boundary of 2-dimensional raster pattern.

\section{DC AND AC FIELD MAPPING}

A Sorenson DC power supply is used to drive magnet with DC current stability of $10^{-3}$. A DTM-141 digital teslameter with a transverse Group3 Hall probe MPT-141 is used to measure transverse and longitudinal field distribution manually. The longitudinal field profiles are shown in Figure 5, dish line is TOSCA calculation and solid line is experimental curve. The TOSCA data is reproduced within $1 \%$ accuracy.

The excitation curve shown in Figure 6 is obtained by measuring central field versus varying current from $2 \mathrm{~A}$ to $40 \mathrm{~A}$.

Lakeshore teslameter (true rms ac response $400 \mathrm{~Hz}$ ) and

. F. W. Bell 4048 Gaussmeter (true rms ac response $12 \mathrm{KHz}$ ) are used to generate rms field mapping when two kinds of drivers power the magnet respectively. The stray field (below 10 Gauss) volume is about $80 \times 90 \times 60 \mathrm{~cm}^{3}$ when the central rms field is 440 Gauss.

\section{AC VIBRATION}

Horizontal and vertical vibration sensors (L-10 Accelerometer, Martin products) are used to obtain quantitative analysis of magnet mechanical vibration caused by low frequency magnetic force generated by driving current in winding. The calibrated output voltage of $\mathrm{L}-10$ is $0.7 \mathrm{~V} /$ (inch/s) when terminated by $75 \mathrm{ohm}, 0.8 \mathrm{~V} /$ (inch $/ \mathrm{s}$ )

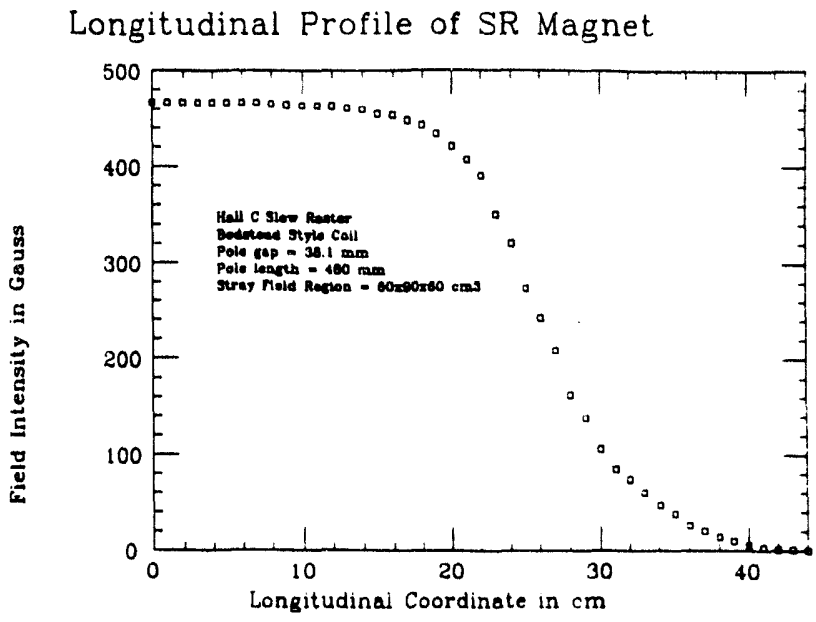

Figure 5: Longitudinal field profiles of slow raster magnet

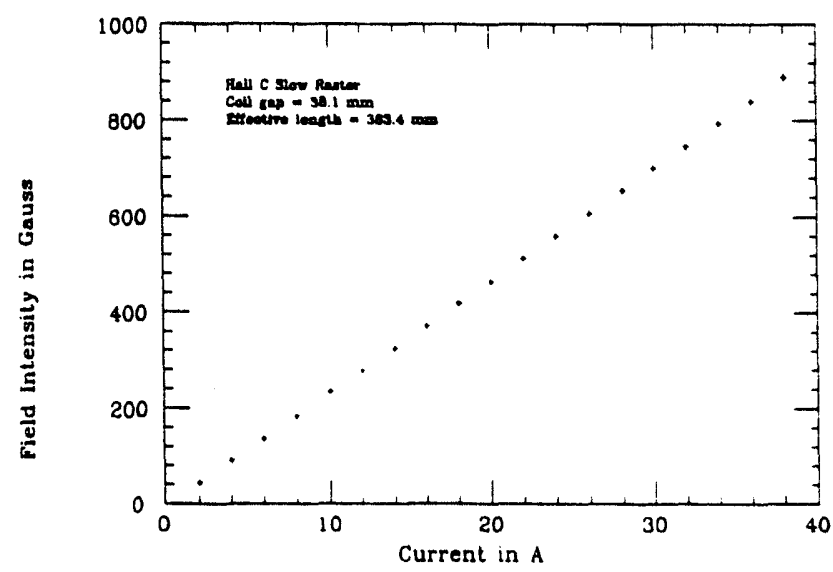

Figure 6: Excitation curve of slow raster 
Table 3: Vibration parameters at $60 \mathrm{~Hz}$

\begin{tabular}{|l|c|c|c|}
\hline Driving peak current (A) & 20 & 30 & 40 \\
Driving rms voltage (V) & 198 & 296.2 & 385.9 \\
Peak central field (Gauss) & 467.6 & 697.2 & 907.0 \\
Horizontal velocity (inch/s) & 0.045 & 0.0725 & 0.105 \\
Vertical velocity (inch/s) & 0.233 & 0.366 & 0.463 \\
Maximum amplitude $(\mu \mathrm{m})$ & 9.7 & 15.25 & 19.29 \\
\hline
\end{tabular}

Table 4: Vibration parameters at $103.4 \mathrm{~Hz}$

\begin{tabular}{|l|c|c|c|c|}
\hline Driving peak current $(\mathrm{A})$ & 14.2 & 20 & 21.5 & 25.28 \\
Horizontal velocity (inch/s) & 0.037 & 0.053 & 0.063 & 0.076 \\
Vertical velocity (inch/s) & 0.207 & 0.295 & 0.327 & 0.384 \\
Maximum amplitude $(\mu \mathrm{m})$ & 6.24 & 8.92 & 9.9 & 11.62 \\
\hline
\end{tabular}

with open ends. Vibration amplitude at $60 \mathrm{~Hz}$ and 103.4 $\mathrm{Hz}$ with different driving current are listed in Table 3 and Table 4.

Even the vibration caused by $\mathrm{AC}$ field of slow raster is in the order of $20 \mu \mathrm{m}$, one should isolate raster magnet from other beam line elements, especially the wire scanners, by installing bellows at two ends of beam pipe of raster magnet and placing a $\mu$-metal shielding cover over the scanner.

\section{BEAM PIPE FOR RASTER MAGNET}

The skin effect of alternate current in a solid conductor is its concentration in a thin layer at the periphery. The effect results from the internal and external distribution of flux lines. At $60-100 \mathrm{~Hz}$ frequency range, penetration depth is $6.5-8.5 \mathrm{~mm}$. Even inside the stainless steel beam pipe the field is not effected by skin effect, the eddy current generated by low frequency alternative field causes large amount of power dissipation on the wall of beam pipe. The temperature of beam pipe increases rapidly (about $40^{\circ} \mathrm{K}$ per minute) when the magnet is powered.

. As a temporary replacement of ceramic pipe, an epoxy pipe is under testing now. Two flanges (one fixed, and one rotatable) are glued to the beam pipe by Torr-Seal

- high vacuum epoxy. After two weeks continuous pumping down by a set of ion pump and turbo pump, the pressure is $5 \times 10^{-6}$, that is still not good enough for normal vacuum operation. As soon as the ceramic duct is manufactured, it will be coated by very thin metal layer (few $\mathrm{M} \Omega$ per inch $^{2}$ ), which is used to release extra charges produced by either beam polarization effect on the wall or scattered electrons, to prevent any accidential damage. The coated ceramic duct will be the permanent beam pipe of slow raster magnets.

\section{REFERENCES}

[1] C. Yan et al, Beam Raster System at CEBAF, CEBAF- 

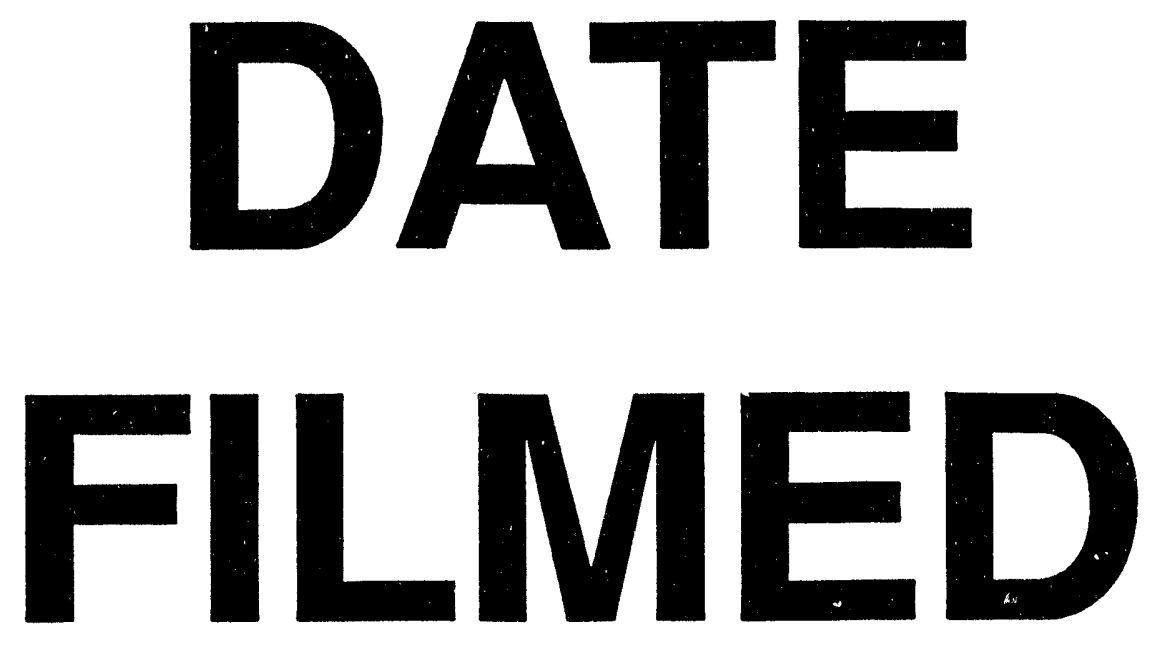

$10 / 18 / 94$
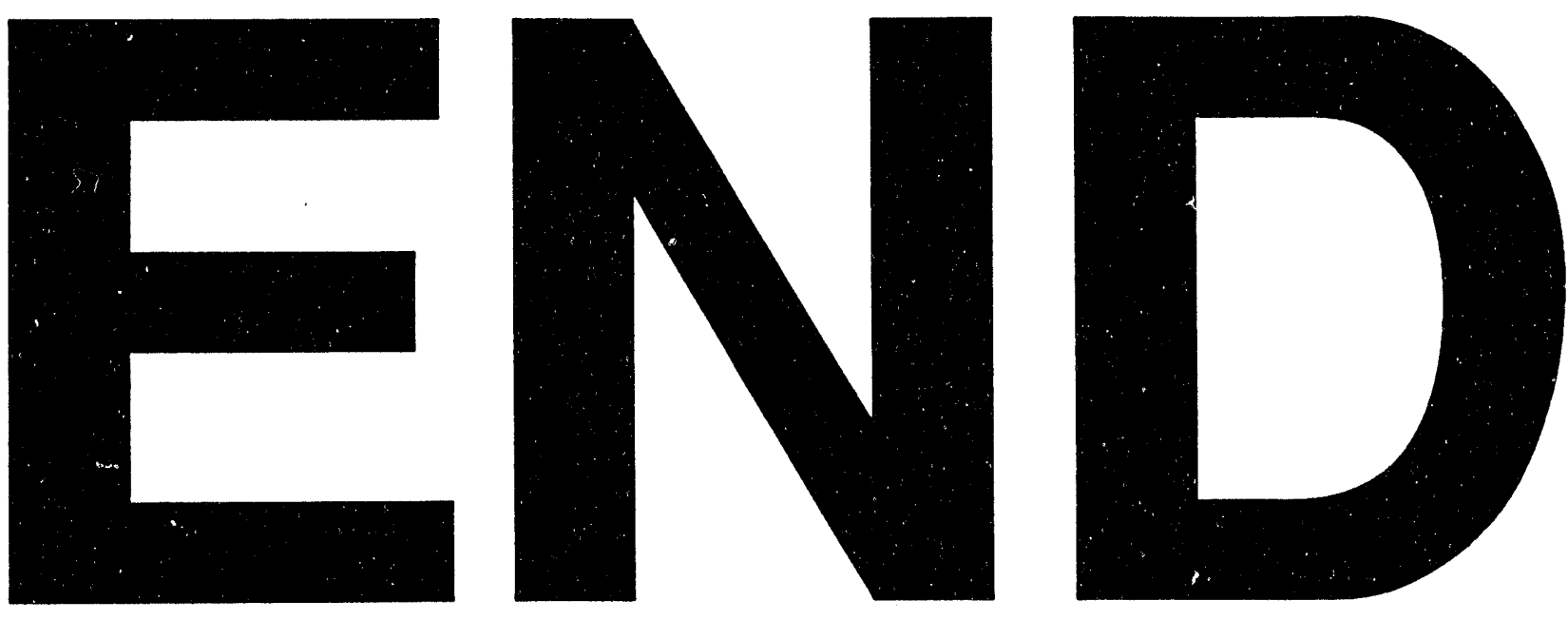
